\title{
The Faster the Better? Delivery Time Preference for Online Shopping: An Abstract
}

\author{
Yi-Fen Liu and I-Ling Ling
}

\begin{abstract}
More and more online retailers are pursuing extremely short delivery time with a belief that it will be an important source of competitive advantages. For example, Amazon is developing octocopters to deliver goods within $30 \mathrm{~min}$ after consumers placing their orders online. Google is also engaging in Project Wing to shorten delivery time to less than $30 \mathrm{~min}$. Shortening delivery time causes challenges in logistics management and increases huge cost for online retailers; however, is it really worthwhile? Do consumers really need to receive the goods so fast? Therefore, this research aims to investigate under what circumstances consumers prefer shorter delivery time and how short is enough. We first conducted in-depth interviews. The results reveal that online shoppers do not always prefer shorter delivery time. The interviewees reported that the average delivery time is 3-4 days and 1-2 days is short enough when they need shorter delivery time. Furthermore, we identified product type (functional product vs. hedonic product), purchase purpose (gift giving vs. self-use), and price discount as key factors influencing consumers' delivery time preference from the interviews. Then the relationships between those variables were tested through two experimental studies. The results of Experiment 1 reveal that online shoppers prefer shorter delivery time when purchasing functional products than hedonic products, and the difference of delivery time preference between two product types is smaller in gift-giving conditions than in self-use conditions. Experiment 2 has shown that in both self-use and gift-giving conditions, the difference of delivery time preference between two product types is smaller when price discount is provided than when no price discount is provided.
\end{abstract}

References Available Upon Request

Y.-F. Liu $(\bowtie)$
National Kaohsiung First University of Science and Technology, Kaohsiung, Taiwan
e-mail: yifenliu@nkfust.edu.tw

I.-L. Ling

National Chiayi University, Chiayi City, Taiwan

e-mail: yiling@mail.ncyu.edu.tw 